\title{
Protective Effects of Curcumin on the Outcome of Cryopreservation in Human Sperm
}

\author{
Marianna Santonastaso ${ }^{1} \cdot$ Filomena Mottola $^{2} \cdot$ Concetta lovine $^{2} \cdot$ Nicola Colacurci $^{1} \cdot$ Lucia Rocco $^{2}$ (I)
}

Received: 6 August 2020 / Accepted: 2 April 2021 / Published online: 16 April 2021

(C) The Author(s) 2021

\begin{abstract}
Cryopreservation causes decreased sperm fertility potential due to reactive oxygen species (ROS) production and physicalchemical damage, resulting in reduced sperm viability and motility. The addition of antioxidants to freezing media could protect sperm from cryo-damage, counteracting the harmful effects of ROS. The aim of this study was to assess the effects of curcumin supplementation in freezing medium on preventing cryo-damage in human semen. Semen samples collected from fertile men were cryopreserved in freezing medium supplemented with different concentrations of curcumin $(2.5,5,10$, and $20 \mu \mathrm{M})$. After freezing-thawing, sperm parameters, DNA fragmentation, intracellular ROS, and glutathione peroxidase 4 (GPX4) gene expression were evaluated. Supplementation with $20 \mu \mathrm{M}$ curcumin in freezing medium caused increases in progressive and nonprogressive motility and significant reductions in intracellular ROS and DNA fragmentation in frozen-thawed sperm cells. Following cryopreservation, GPX4 mRNA expression was significantly upregulated in thawed semen supplemented with $20 \mu \mathrm{M}$ curcumin compared to the control. The results showed that curcumin supplementation in freezing medium was protective against human sperm parameters and sperm DNA, counteracting oxidative damage induced by the freeze-thaw process.
\end{abstract}

Keywords Sperm quality $\cdot$ Curcumin $\cdot$ Sperm cryopreservation $\cdot$ Glutathione peroxidase $4 \cdot$ Oxidative stress $\cdot$ Sperm DNA fragmentation

\section{Introduction}

Human sperm cryopreservation is a widely used practice in assisted reproductive technology (ART) centres for various reasons, such as fertility preservation before cancer treatment [1]; spermatozoa storage to overcome oligozoospermic and azoospermic conditions, percutaneous epididymal sperm aspiration (PESA) or testicular sperm extraction (TESE) due to ejaculatory dysfunction or spinal cord injury; or sperm donation [2].

Freezing and thawing procedures have adverse effects on sperm structure and function, reducing sperm viability, motility and longevity in the female genital tract and consequently

Lucia Rocco

lucia.rocco@unicampania.it

1 Department of Woman, Child and General and Special Surgery, University of Campania "Luigi Vanvitelli", Napoli, Italy

2 Department of Environmental, Biological and Pharmaceutical Sciences and Technologies, University of Campania "Luigi Vanvitelli", Caserta, Italy decreasing fertility potential [3]. Throughout the freezing and warming processes, spermatozoa are exposed to physical and chemical stresses that result in excessive dehydration, plasma membrane disintegration, acrosome leakage, mitochondrial injury, metabolic-functional changes, and DNA fragmentation [4-8]. This sperm cryo-damage is mediated by reactive oxygen species (ROS) production [9-11]. ROS can alter the sperm antioxidant defence system, resulting in lipid peroxidation, membrane fluidity reduction, membrane enzyme and ion channel inactivity, decreased sperm motility, increased apoptosis, sperm-oocyte fusion defects, early miscarriage and embryonic genetic mutations $[12,13]$.

Antioxidants are molecules that are able to inhibit or reduce oxidative processes by scavenging released free radicals [14]. Several antioxidants have been suggested to be helpful in male infertility treatment to counteract ROS and preserve sperm motility, viability and functionality, such as vitamins $\mathrm{E}$ and $\mathrm{C}$, as well as selenium $(\mathrm{Se})$, zinc $(\mathrm{Zn})[15,16]$ and ellagic acid [17]. Moreover, antioxidants have shown positive effects on sperm cryopreservation; the addition of vitamin $\mathrm{E}$ in freezing medium significantly reduces sperm ROS levels following the thawing process [18]. 
For this reason, enriching culture freezing systems with antioxidants could be an effective approach to counteract sperm damage induced by cryopreservation [19-27].

Curcumin, a type of antioxidant, is a yellow phenolic pigment that is a component of the rhizome of Curcuma longa with a broad range of biological and pharmacological functions, such as anti-inflammatory, antineoplastic, antioxidant and anti-mutagenic activities [28-30]. The safety of curcumin was reported by the United States Food and Drug Administration [31]. Curcumin presents a dual mechanism of action as an antioxidant; one mechanism is due to its chemical structure, and the other is linked to its ability to stimulate the production of antioxidant enzymes. Curcumin contains different functional antioxidant groups, such as $\beta$-diketo groups, carbon-carbon double bonds and phenyl rings [32]. The antioxidant activity of curcumin was also associated with its phenolic and/or central methylenic groups [33, 34], while its chelating activity and ability to capture ferrous ions are due to functional carbonyl groups [32]. Moreover, curcumin exhibits antioxidant activity by regulating transcription factors and antioxidant enzymes, such as haem oxygenase-1 (HO-1) and nuclear factor erythroid 2-related factor 2 (Nrf2), upregulating common antioxidative activities (superoxide dismutase (SOD) and glutathione (GSH)) and inhibiting cytokine production (e.g. interleukin- $1 \beta$ (IL-1 $\beta$ ), tumour necrosis factor- $\alpha$ (TNF- $\alpha$ ) and interleukin 12 (IL-12)) [35-37].

In sperm cells, curcumin improved capacitation, acrosome reaction and fertilization in vitro and in vivo [38-40]. This antioxidant could increase sperm motility in patients with leucocytospermia and improve semen parameters in asthenoteratospermia by regulating the levels of the transcription nuclear factor Nrf2 [41].

Curcumin has a protective effect against spermatogenesis defects induced by titanium dioxide nanoparticles $\left(\mathrm{n}-\mathrm{TiO}_{2}\right)$ [42] and restores testicular damage induced by alcohol, cisplatin, aflatoxin, metronidazole, ischaemia reperfusion and cadmium exposure in mice [43-48]. It also improves the histopathological alterations induced by monosodium glutamate in the testis and epididymis, increasing sperm count in rats [49].

The positive effects of curcumin supplementation on sperm freezing media have been reported in various animal models, such as Angora goats, bulls, Wistar mice and buffalos [21, $50-52]$. It has been reported that curcumin could improve bull spermatozoa and rat testes subjected to induced oxidative stress and could improve cryopreserved boar spermatozoa, increasing progressive motility and acrosome integrity [53-55].

In rams, curcumin had protective effects on frozen-thawed sperm parameters at different doses; antioxidant supplementation resulted in a higher percentage of sperm acrosome integrity and provided strong protection in terms of sperm mitochondrial activity in comparison to the control [56].
These data have led to the hypothesis that curcumin may have an effect on preventing human sperm damage induced by cryopreservation, so the aim of this study was to test the effects of curcumin in preventing cryo-damage during the freeze/thaw process of sperm from fertile men. To date, no studies concerning this property have been carried out on human spermatozoa. We evaluated the effects of different concentrations $(2.5,5,10$ and $20 \mu \mathrm{M})$ of curcumin supplementation in freezing medium on human sperm parameters, intracellular ROS, DNA fragmentation and glutathione peroxidase 4 (GPX4) antioxidant gene expression after freeze-thaw cycling. Glutathione peroxidase (GPX4), which encodes the glutathione peroxidase $4(\mathrm{Gpx} 4)$ protein, protects cells from oxidative stress caused by cell membrane peroxidation. Gpx4 is important for normal spermatozoa development, as it protects sperm cells from oxidative stress and is a necessary structural protein in mature spermatozoa, and Gpx4 expression alterations are associated with male infertility $[57,58]$.

\section{Materials and Methods}

\section{Chemicals}

Curcumin powder was supplied by Sigma-Aldrich (CAS number 458-37-7). Curcumin stock solution $(0.1 \mathrm{M})$ was prepared using $96 \%$ ethanol as a solvent.

\section{Sample Collection and Analysis}

The subjects were recruited from our Reproduction Biology Laboratory (University of Campania "Luigi Vanvitelli"). We did not require approval from the Ethics Committee because the study involved neither therapeutic interventions nor any change to our routine sperm analysis; moreover, written informed consent was obtained from each subject before their inclusion in the study. Subjects with any history of drug addiction, smoking or alcohol consumption, prolonged diseases such as varicocele or drug consumption, including antioxidant consumption, were not included. The ejaculates were collected from men between 30 and 42 years old $(36.5 \pm 6.2$ years old mean age) by masturbation after 3-5 days of recommended abstinence. After liquefaction at room temperature for 30 minutes (min), the semen volume, sperm concentration, viability, motility and morphology were determined according to the 2010 WHO guidelines [59]. Sperm motility was evaluated by optical microscopy at $400 \times$ magnification and was classified according to WHO guidelines 2010 as progressive, nonprogressive or immotile. Sperm viability was examined using eosin-nigrosin staining, while sperm morphology was evaluated on Testsimplets ${ }^{\circledR}$ (ORIGIO, Italia) prestained slides. For the study, we selected 60 ejaculates with good semen parameters according to the $2010 \mathrm{WHO}$ guidelines (Table 1). 
Table 1 Parameters of semen selected for the study $(n=60)$. Sperm parameters were expressed as mean $\pm \mathrm{SD}$

\begin{tabular}{ll}
\hline Sperm parameters & Mean $\pm \mathrm{SD}$ \\
\hline Semen volume $(\mathrm{mL})$ & $3.16 \pm 1.43$ \\
Sperm concentration $\left(\times 10^{6} \mathrm{sperm} / \mathrm{mL}\right)$ & $65.36 \pm 23.94$ \\
Motility $(\%)$ & \\
Progressive & $49.67 \pm 4.66$ \\
Non-progressive & $27.0 \pm 8.51$ \\
Immotile & $23.33 \pm 11.44$ \\
Normal morphology $(\%)$ & $24.42 \pm 8.62$ \\
Viability $(\%)$ & $78.75 \pm 10.18$ \\
\hline
\end{tabular}

\section{Exposure Procedure}

The pooled samples $(n=60)$ were divided into five aliquots $\left(10 \times 10^{6} \mathrm{sperm} / \mathrm{mL}\right)(n=12$ for each group $)$ and frozen in the presence of freezing medium plus different concentrations of curcumin: 0 (vehicle control group), $2.5 \mu \mathrm{M}, 5 \mu \mathrm{M}, 10 \mu \mathrm{M}$ and $20 \mu \mathrm{M}$. In the vehicle control group, ethanol was added at the same concentration used to dissolve curcumin in each group. We added $3.4 \mu \mathrm{L}$ of curcumin stock solution to 1.7 $\mathrm{mL}$ of sample/freezing medium mixture in the $20 \mu \mathrm{M}$ curcumin group; $1.7 \mu \mathrm{L}$ of curcumin stock solution to the sample/freezing medium mixture in the $10 \mu \mathrm{M}$ curcumin group; and $0.85 \mu \mathrm{L}$ and 0.425 of curcumin stock solution to the sample/freezing medium mixture in the $5 \mu \mathrm{M}$ and $2.5 \mu \mathrm{M}$ curcumin groups, respectively. The sperm freezing procedures are described below. After 7 days of freezing, followed by thawing, as described below, the samples were analysed for sperm motility, viability, DNA fragmentation, intracellular ROS levels and GPX4 gene expression. All experiments were performed in triplicate.

\section{Sperm Freezing and Thawing}

The sperm freezing and thawing procedure was conducted according to the manufacturer's instructions (SpermFreeze, FertiPro N.V., Beernem, Belgium). Briefly, $1 \mathrm{~mL}$ of sample was diluted dropwise with $0.7 \mathrm{~mL}$ of freezing medium (SpermFreeze, FertiproN.V., Beernem, Belgium). The medium is a commercial cryoprotectant consisting of $15 \%$ glycerol in 4-(2-hydroxyethyl)-1-piperazine ethanesulfonic acid (HEPES) buffer supplemented with human serum albumin (HSA). After $30 \mathrm{~min}$ for the equilibration of the sample/ medium mixture at room temperature, the mixture was transferred into cryovials (Thermo Scientific Nunc, Denmark). The cryovials were set into a metal surface under liquid nitrogen vapour for $15 \mathrm{~min}$ (slowly frozen) and then immersed in liquid nitrogen $\left(-196{ }^{\circ} \mathrm{C}\right.$ liquid nitrogen) for storage.
After cryostorage for 7 days, the samples were thawed in a tap water container at $37{ }^{\circ} \mathrm{C}$ for $4-5 \mathrm{~min}$. Then, the sperm samples were resuspended in sperm washing medium (FertiPro N.V., Beernem, Belgium) and centrifuged at 1500 revolutions per minute (rpm) for $5 \mathrm{~min}$. The sperm pellet was resuspended in sperm washing medium (FertiPro N.V., Beernem, Belgium) and analysed for sperm motility, viability, DNA fragmentation, intracellular ROS levels and GPX4 gene expression.

\section{Intracellular ROS Measurement}

Intracellular sperm ROS levels were quantified by a DCF assay with a 2,7-dichlorodihydrofluorescein diacetate $\left(\mathrm{DCFH}_{2}-\mathrm{DA}\right)$ probe according to Santonastaso et al. [60]. $\mathrm{DCFH}_{2}$-DA (13 $\mu \mathrm{M}$, Sigma-Aldrich) was added to a $150-\mu \mathrm{L}$ semen sample and incubated at 37 ${ }^{\circ} \mathrm{C}$ for $30 \mathrm{~min}$ in the dark. After washing in $1 \times$ phosphate-buffered saline (PBS, Sigma-Aldrich), the sperm cells were counterstained with 4',6-diamidino-2'phenylindole dihydrochloride (DAPI, Sigma-Aldrich) solution and analysed under a fluorescence microscope (Nikon Eclipse E-600) equipped with BP 330-380 nm and LP $420 \mathrm{~nm}$ filters. Intracellular ROS was visually scored and measured as the percentage of sperm cells exhibiting a response (green cells) to total sperm cells. DCF assay was performed in triplicate.

\section{Sperm DNA Fragmentation Assessment}

DNA fragmentation was determined using an In Situ Cell Death Detection Kit (Roche Diagnostics) according to Santonastaso et al. [61]. Fifteen microlitres of sample was placed on glass slides, fixed in $4 \%$ paraformaldehyde for $1 \mathrm{~h}$ at room temperature and air dried. After 2 min of incubation in permeabilizing solution (sodium citrate, distilled $\mathrm{H}_{2} \mathrm{O}$ and Triton $\mathrm{X}-100$ ), the glass slides were washed in $1 \times$ PBS and air dried, and then, the TUNEL reaction mixture $(5 \mu \mathrm{L}$ of enzyme terminal deoxynucleotidyl transferase solution and $45 \mu \mathrm{L}$ of label solution) was placed on the slides. Each slide was incubated for $1 \mathrm{~h}$ at $37{ }^{\circ} \mathrm{C}$ in a humid chamber, stained with DAPI solution for $5 \mathrm{~min}$ and analysed under a fluorescence microscope (Nikon Eclipse E-600) equipped with $330-380 \mathrm{~nm}$ BP and $420 \mathrm{~nm}$ LP filters. Cells with fragmented DNA emitted green fluorescence, while those with intact DNA emitted blue fluorescence due to DAPI. We counted 300-500 cells per slide, distinguishing those with fragmented DNA (green fluorescence) from those with intact DNA (blue fluorescence). The TUNEL assay was performed in triplicate. 


\section{Total RNA Isolation, cDNA Synthesis and Quantitative Real-Time Polymerase Chain Reaction}

An SV Total RNA Isolation System (Promega) kit was used to extract total RNA from sperm cells $\left(2 \times 10^{6}\right.$ spermatozoa), and through the use of the GoScript Reverse Transcription System (Promega), $500 \mathrm{ng}$ of total RNA was reverse transcribed into a $25 \mu \mathrm{L}$ of first-strand cDNA pool following the instructions provided by the manufacturer.

Quantitative real-time polymerase chain reaction (qPCRRT) was performed in a total volume of $10 \mu \mathrm{L}$ using the iTaqTM Universal SYBR® Green One-Step Kit (Bio-Rad) comprising the dsDNA binding fluorophore (SYBR Green), thermostable polymerase, magnesium ions and deoxynucleotide triphosphates (dNTPs). The reaction mixture contained $5 \mu \mathrm{L}$ of $1 \times$ Master Mix, $1 \mu \mathrm{L}$ of forward primer $(50$ $\mu \mathrm{M}), 1 \mu \mathrm{L}$ of reverse primer $(50 \mu \mathrm{M})$ (Table 2$)$ and $80 \mathrm{ng}$ of complementary DNA (cDNA). Human GPX4 sequences were obtained from GenBank and designed with Primer3 software. The reactions were carried out in triplicate and run on an iCycler Thermal Cycler w/iQ5 Multicolour Real-Time PCR Detection (Bio-Rad) under the following conditions: $95^{\circ} \mathrm{C}$ for 10 min for enzyme activation and DNA denaturation; 40 cycles of $95^{\circ} \mathrm{C}$ for $15 \mathrm{~s}$ and $55^{\circ} \mathrm{C}$ for $1 \mathrm{~min}$; and finally, $60{ }^{\circ} \mathrm{C}+$ $0.5^{\circ} \mathrm{C}$ for $10 \mathrm{~min}$. Fluorescence intensities were analysed using the manufacturer's CFX Manager (Bio-Rad) software. The relative quantification of GPX4 mRNA expression detectable in human sperm cells $[62,63]$ was calculated using the $2^{-\Delta \Delta C t}$ method and normalized according to the expression of $\beta$-actin as a housekeeping gene. The specificity of the products was evaluated by melting curve analysis [64].

\section{Statistical Analysis}

All sperm parameters are expressed as the mean \pm standard deviation (SD). Differences in the DNA fragmentation index (DFI) and intracellular ROS among the experimental groups were analysed using unpaired Student's $t$ test with the software package GraphPad Prism 6 [65]. The effect was considered significant if the $p$ value was $\leq 0.05$ with respect to the vehicle control.

Table 2 Real-time q-PCR primers. F: forward primer; R: reverse primer; GPX4: glutathione peroxidase 4; $\beta$-ACT: $\beta$-actin

\begin{tabular}{ll}
\hline Gene & Primer sequence (5' to $\left.3^{\prime}\right)$ \\
\hline$G P X 4$ & F: TCA GCA AGA TCT GCG TGA AC \\
& R: CCG GAT GCC ATA GTC AGG AT \\
$\beta-A C T$ & F: GGA CTT CGA GCA AGA GAT GG \\
& R: AGC ACT GTG TTG GCG TAC AG \\
\hline
\end{tabular}

\section{Results}

\section{Sperm Viability and Motility}

No significant difference was observed in the percentage of viable sperm after thawing when each curcumin group (2.5 $\mu \mathrm{M}, 5 \mu \mathrm{M}, 10 \mu \mathrm{M}$ and $20 \mu \mathrm{M}$ ) was compared with the vehicle control group. Our results showed that total motility (progressive and nonprogressive) was significantly higher in the $20 \mu \mathrm{M}$ curcumin-treated group than in the vehicle control group ( $p$ value $\leq 0.05$ ) after thawing. In particular, a significant increase in spermatozoa with progressive motility was observed in the $20 \mu \mathrm{M}$ curcumin sperm group. No significant difference in sperm motility was observed between the 2.5 $\mu \mathrm{M}, 5 \mu \mathrm{M}$ and $10 \mu \mathrm{M}$ curcumin-treated sperm groups and the control group (Table 3).

\section{Intracellular ROS Assessment}

The results obtained by DCF assay showed that the sperm intracellular ROS percentage was significantly lower in the groups treated with $20 \mu \mathrm{M}$ curcumin than in the vehicle control group ( $p$ value $\leq 0.05$ ). No significant difference was seen in the percentage of ROS production when the $2.5 \mu \mathrm{M}, 5 \mu \mathrm{M}$ and $10 \mu \mathrm{M}$ curcumin-treated groups were compared with the vehicle control group (Figs. 1 and 2).

\section{Sperm DNA Fragmentation Evaluation}

The TUNEL assay results revealed a decrease in sperm DNA fragmentation when curcumin was added to freezing medium. After thawing, the DFI was significantly lower ( $p$ value $\leq$ 0.05 ) in the group treated with $20 \mu \mathrm{M}$ curcumin than in the vehicle control group. No significant difference in DFI was observed in the $2.5 \mu \mathrm{M}, 5 \mu \mathrm{M}$ and $10 \mu \mathrm{M}$ curcumin-treated groups compared with the vehicle control groups (Figs. 3 and 4).

\section{Sperm GPX4 mRNA Expression}

Sperm cells frozen with freezing medium plus $20 \mu \mathrm{M}$ curcumin had significantly higher GPX4 mRNA levels than sperm cells frozen without curcumin ( $p$ value $\leq 0.05$ ), whereas the GPX4 mRNA levels after thawing in the $2.5 \mu \mathrm{M}, 5 \mu \mathrm{M}$ and $10 \mu \mathrm{M}$ curcumin-treated groups were not significantly different from those in the vehicle control group (Fig. 5).

\section{Discussion and Conclusions}

Sperm cryopreservation guarantees male gamete selfconservation to preserve fertility. It is well known that these procedures impair sperm quality, reducing sperm fertilizing 
Table 3 Effect of curcumin concentrations $(2.5,5,10$ and $20 \mu \mathrm{M})$ added to freezing medium on progressive motility (PR) and total motility (progressive + nonprogressive (NP)) and viability. The values were expressed as mean $\pm \mathrm{SD}$. ${ }^{*} p \leq 0.05$

\begin{tabular}{llll}
\hline Treatments & Progressive motility (PR) $(\%)$ & Total motility (PR+ NP) $(\%)$ & Viability $(\%)$ \\
\hline Control (freezing medium) & $28.15 \pm 3.50$ & $42.59 \pm 4.45$ & $50.57 \pm 10.28$ \\
$2.5 \mu \mathrm{M}$ Curcumin (freezing medium + curcumin $2.5 \mu \mathrm{M})$ & $27.78 \pm 5.00$ & $40.35 \pm 2.57$ & $51.23 \pm 8.56$ \\
$5 \mu \mathrm{M}$ Curcumin (freezing medium + curcumin $5 \mu \mathrm{M})$ & $26.50 \pm 4.05$ & $39.75 \pm 5.65$ & $49.76 \pm 9.87$ \\
$10 \mu \mathrm{M}$ Curcumin (freezing medium + curcumin $10 \mu \mathrm{M})$ & $35.65 \pm 3.12$ & $51.71 \pm 5.36$ & $54.78 \pm 11.23$ \\
$20 \mu \mathrm{M}$ Curcumin (freezing medium + curcumin $20 \mu \mathrm{M})$ & $47.20 \pm 5.80^{*}$ & $65.00 \pm 3.73 *$ & $56.35 \pm 12.03$ \\
\hline
\end{tabular}

ability [26, 66, 67]. The major biological problem of sperm cryopreservation is due to the alteration of normal cellular mechanisms: sperm cells exposed to low temperatures undergo irreversible damage that causes decreases in motility and fertility potential [68].

The success of sperm freezing depends on internal sperm parameters and external factors such as the composition of the diluent, type and concentration of cryoprotectants, dilution rates and cooling, equilibration, freezing and thawing procedures [69]. Cryoprotectants and suitable freezing and thawing procedures protect sperm from dehydration, increased salt concentrations and thermal shock to safeguard cell membrane integrity and to optimize the osmolarity of extracellular fluids [70]. However, the presence of cryoprotectants is not enough
Fig. 1 Intracellular ROS (green cell) in human sperm cells analysed by fluorescence microscopy using the $\mathrm{DCFH}_{2}$ DA probe in different treatment groups: a vehicle control; b $2.5 \mu \mathrm{M}$ curcumin-treated group; $\mathbf{c}$ $5 \mu \mathrm{M}$ curcumin-treated group; $\mathbf{d}$ $10 \mu \mathrm{M}$ curcumin-treated group; $20 \mu \mathrm{M}$ curcumin-treated group
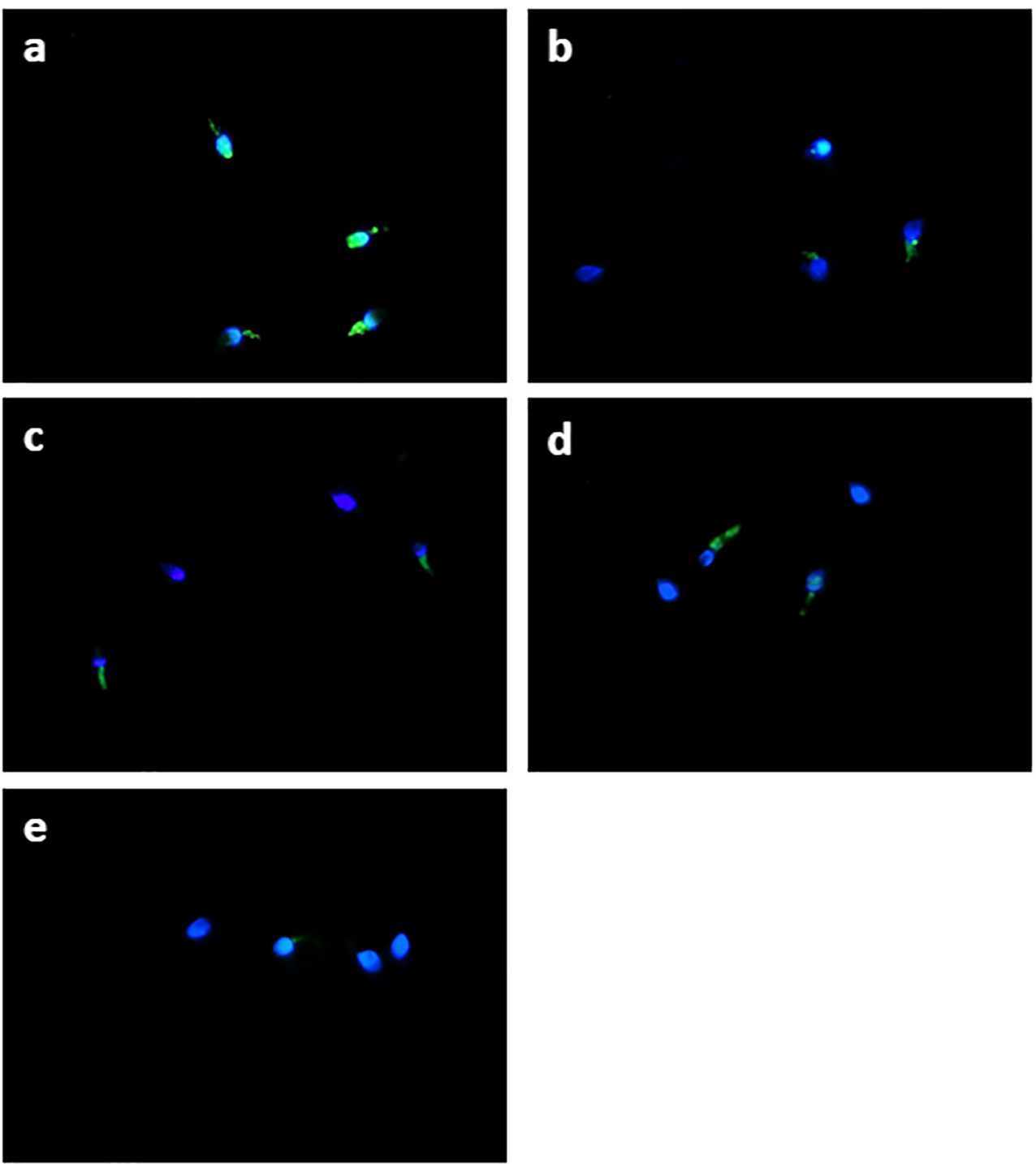
DCF Assay

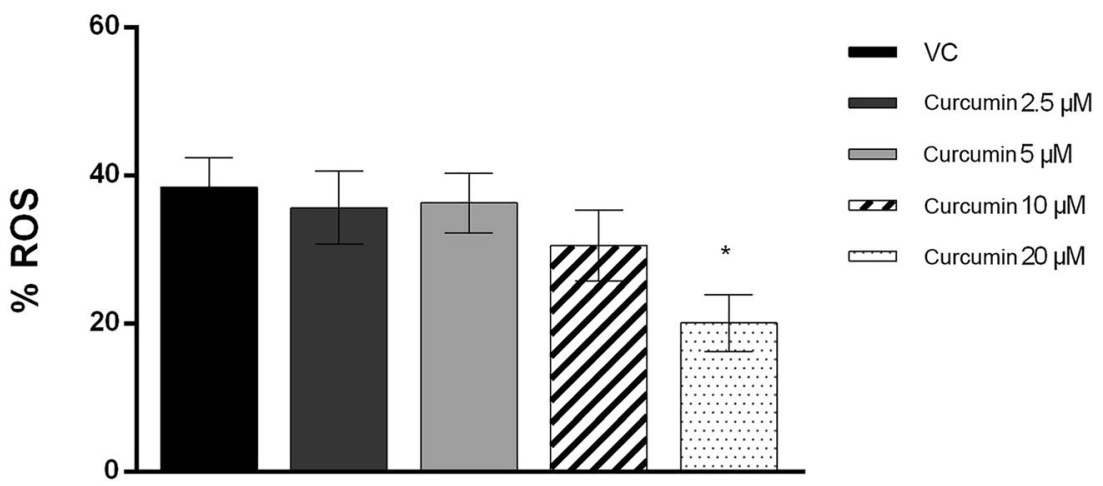

Fig. 2 Percentage of intracellular ROS (ordinate) in human sperm cells in the different treatment groups $(n=12)$ (abscissa) after the thawing procedure. The black bars are vehicle controls (VC); the dark grey bars are the $2.5 \mu \mathrm{M}$ curcumin-treated group (curcumin 2.5); the light grey bars are

to protect cells from the stress induced by the freezing process, which in most cases involves membrane integrity loss, mitochondrial damage, metabolic and functional status alterations $[8,71]$, lipid peroxidation and increased cytoplasmic ROS and DNA damage [72]. However, small amounts of ROS are important for sperm maturation; in fact, sperm ROS play an important role in capacitation, the acrosomal reaction, mitochondrial stabilization and motility [73].

The disruption of the balance between ROS and antioxidant scavenging could provoke oxidative stress. Human sperm are very sensitive to free oxygen radical toxicity, and the main consequence is lipid peroxidation [74]. The most dangerous products of lipid peroxidation are malondialdehyde (MDA) and 4-hydroxynonenal (4-HNE), which can cause severe protein dysfunction and DNA damage, recruiting leukocytes by chemotactic activity and inhibiting cell proliferation. Given the low efficiency of the intracellular systems of sperm gene repair, the only protective mechanism is the tight packing of the genome and the antioxidants present in the male genital tract and in the seminal plasma [75]. Nfr2 plays a critical role in the defence against oxidative stress by inducing the expression of antioxidant proteins and phase II detoxification enzymes as well as of genes encoding catalase (Cat), superoxide dismutase, glutathione S-transferase (GST) and haem oxygenase-1 [76]. Nonenzymatic and natural antioxidants also play an important role in the protection of male gametes the $5 \mu \mathrm{M}$ curcumin-treated group (Curcumin 5); the striped bars are the $10 \mu \mathrm{M}$ curcumin-treated group (Curcumin 10); and the dotted bars are the $20 \mu \mathrm{M}$ curcumin-treated group (Curcumin 20). The error bars represent \pm standard deviation (SD). $* p \leq 0.05$

and are able to counteract DNA damage both in vivo and in vitro [77].

Antioxidants seem to be of great clinical importance, as they reduce ROS and oxidative stress and, as a result, improve fertility potential both in natural pregnancy and in ART; they can also play a protective role during embryonic development [78].

Antioxidant supplementation can potentially improve sperm cryopreservation outcomes. The addition of $5 \%$ sericin to freezing and thawing media increased total motility and viability and decreased DNA fragmentation relative to media without sericin [79]. Melatonin may exert its cryoprotective effects on spermatozoa by counteracting intracellular ROS and thereby reducing MDA generation, leading to an increase in the post-thaw viability and motility of cryopreserved human spermatozoa [68] and reducing oxidative damage by upregulating heat shock protein 90 (HSP-90) expression [80]. Supplementation of the cryopreservation medium with quercetin induced a significant improvement in post-thaw sperm motility, viability and DNA integrity; however, it had no effect on caspase 3 activation [81].

Considering the antioxidant properties of curcumin and its capacity to improve semen quality parameters in asthenoteratospermic men by reducing oxidative stress [38, $82,83]$, we evaluated the effects of curcumin $(2.5 \mu \mathrm{M}, 5$
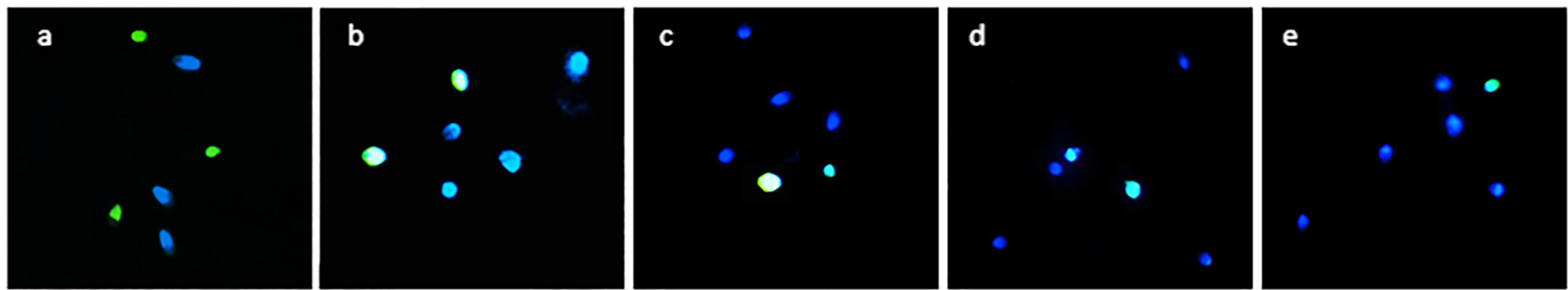

Fig. 3 Human sperm DNA fragmentation as analysed by a TUNEL assay in the different treatment groups: a vehicle control; b $2.5 \mu \mathrm{M}$ curcumin-

treated group; $\mathbf{c} 5 \mu \mathrm{M}$ curcumin-treated group; $\mathbf{d} 10 \mu \mathrm{M}$ curcumin-treated group; $20 \mu \mathrm{M}$ curcumin-treated group 
TUNEL Assay

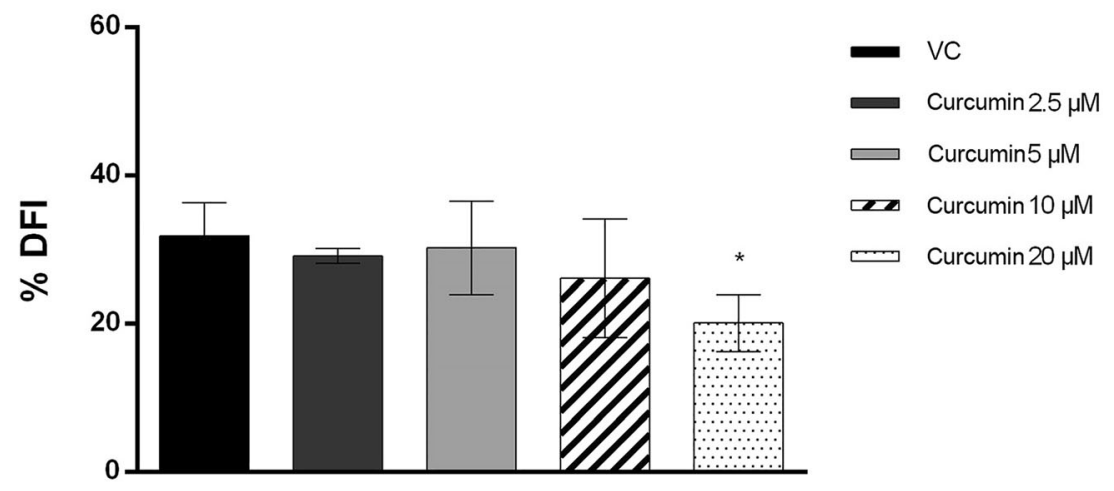

Fig. 4 DNA fragmentation index (ordinate) in human sperm cells in different treatment groups $(n=12)$ (abscissa) after the thawing procedure. The black bars are vehicle controls (VC); the dark grey bars are the $2.5 \mu \mathrm{M}$ curcumin-treated group (Curcumin 2.5); the light grey bars are

$\mu \mathrm{M}, 10 \mu \mathrm{M}$ and $20 \mu \mathrm{M}$ ) supplementation in freezing medium on frozen-thawed human sperm cells.

Our data showed that, among the concentrations tested, $20 \mu \mathrm{M}$ curcumin had positive effects on sperm quality after the freezing-thawing procedure compared to the controls. In particular, the protective effects of $20 \mu \mathrm{M}$ curcumin have been highlighted as increasing sperm total motility, with the improvement of the progressive motility, and reducing intracellular ROS production, proving that this antioxidant is able to protect sperm cells from oxidative damage induced by cryopreservation and improve semen quality after thawing.

The results obtained by the TUNEL assay showed that the sperm DFI was decreased in the curcumin-treated group compared to the frozen sperm group without curcumin added to the cryopreservation medium, and $20 \mu \mathrm{M}$ curcumin even reduced the DFI below the $26 \%$ threshold, the value above which the fertilizing capacity of fresh spermatozoa is drastically reduced [84]. Moreover, the maximum concentration of curcumin tested was able to induce increased GPX4 gene expression and consequently enhance the cellular physiological the $5 \mu \mathrm{M}$ curcumin-treated group (Curcumin 5); the striped bars are the $10 \mu \mathrm{M}$ curcumin-treated group (Curcumin 10); and the dotted bars are the $20 \mu \mathrm{M}$ curcumin-treated group (Curcumin 20). The error bars represent \pm standard deviation (SD). * $p \leq 0.05$

enzyme antioxidant system and decrease sperm DNA fragmentation, thereby reducing sperm apoptotic processes. This result indicates that curcumin not only is able to directly defend sperm from ROS attack but also acts at the molecular level, enhancing the intrinsic defences of the cells.

Modulating GPX4 gene expression in sperm cells is a key factor in preserving male fertility $[62,63]$. Gpx4 can be found in the cytosol and bound to sperm membranes or in other cells of the male genital tract $[85,86]$. It is the only isoform capable of inactivating phospholipid hydroperoxides regardless of the release of fatty acids by phospholipase A2 and is therefore the only antioxidant enzyme capable of repairing some of the damage caused by radicals to macromolecules such as proteins or membrane lipids [87]. Another important function of Gpx4 is oxidation of protamine thiol groups with the formation of disulfide bridges essential for nuclear chromatin condensation and with a structural role creating a network of protein bonds typical of the capsular structure [88-90]. Therefore, in addition to its antioxidant action, Gpx4 has a key role in sperm maturation through the metabolism of

GPX4

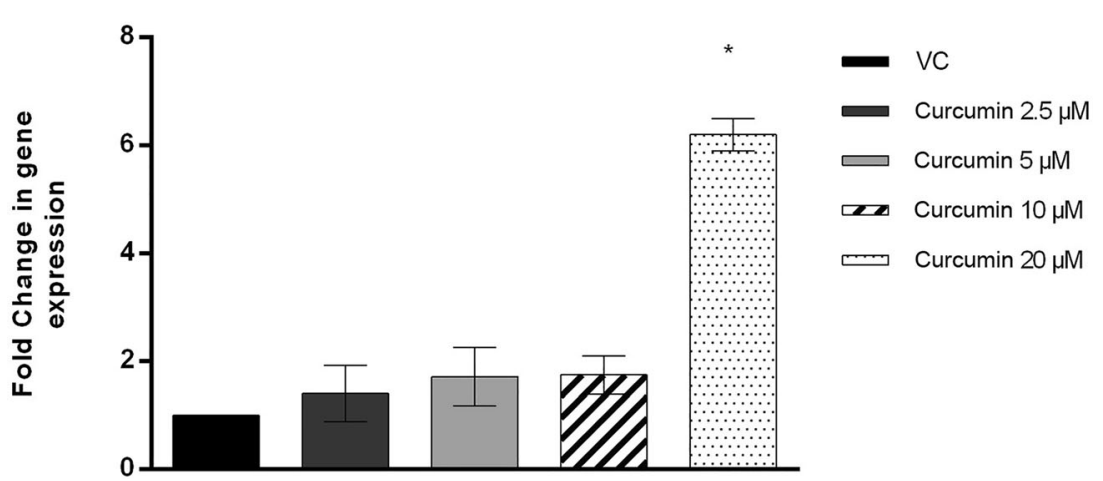

Fig. 5 RT-qPCR analysis of GPX4 (ordinate) in human spermatozoa in different treatment groups $(n=12)$ (abscissa) after the thawing procedure. The black bars are vehicle controls (VC); the dark grey bars are the $2.5 \mu \mathrm{M}$ curcumin-treated group (Curcumin 2.5); the light grey bars are

the $5 \mu \mathrm{M}$ curcumin-treated group (Curcumin 5); the striped bars are the $10 \mu \mathrm{M}$ curcumin-treated group (Curcumin 10); and the dotted bars are the $20 \mu \mathrm{M}$ curcumin-treated group (Curcumin 20). The error bars represent \pm standard deviation (SD). $* p \leq 0.05$ 
hydroperoxides and oxidation of nuclear protamine [91, 92]. Moreover, the expression of Gpx4 has been correlated with the stability of sperm chromatin and with impaired spermatogenesis because it is associated with apoptotic mitochondrial pathways $[93,94]$.

Our results were in agreement with the findings of studies on the ameliorative effect of curcumin on the motility, viability, total antioxidant capacity (TAC) and DNA integrity of frozen-thawed rat sperm and the protective effect of curcumin on dog sperm from damage caused by cryopreservation procedures, improving sperm parameters and protecting sperm against ROS and increasing NADPH oxidase 5 (NOX5) gene expression $[51,95]$. Similarly, in vitro supplementation of bull semen extender with curcumin was able to improve sperm motility (in particular, progressive motility) and protected the sperm from damage induced by oxidative stress [96]. We suggest that the radical scavenging activity of curcumin dose-dependently increased with increasing curcumin concentration, whereas sperm motility, ROS production, DFI and GPX4 gene expression were not significantly different between the control group and the groups treated with low concentrations $(2.5 \mu \mathrm{M}, 5 \mu \mathrm{M}$ and $10 \mu \mathrm{M})$ of curcumin. On the other hand, Zhou et al. showed that curcumin might improve asthenozoospermia by reducing ROS reproduction and regulating Nrf2 levels. They also indicated that curcumin can ameliorate sperm motility in a dose-independent manner and could induce toxicity to sperm motility when applied beyond a certain concentration; $100 \mathrm{nM}$ curcumin significantly increased sperm motility by reducing ROS and apoptosis, while treatment with curcumin at concentrations of $1 \mathrm{mM}$ and $1 \mathrm{M}$ decreased sperm total and progressive motility compared to those of the control group [41].

In any case, at certain concentrations, curcumin can improve sperm parameters due to its ability to scavenge free radicals as an antioxidant through its phenolic, $\beta$-diketone and methoxy functional groups. Curcumin can also uncouple the keap1-Nrf2 complex, which leads to Nrf2 stabilization and subsequent transport into cell nuclei, leading to the transcription of several antioxidant genes involved in antioxidant responses [97-100]. Curcumin may also influence sperm motility, capacitation and function by inhibiting tyrosine phosphorylation of sperm surface proteins and $\mathrm{Ca}^{2+}$ channels, acidifying the intracellular $\mathrm{pH}$ of sperm and hyperpolarizing the sperm cell membrane [101].

In this study, we chose to evaluate the antioxidant ability of freezing medium supplemented with low concentrations of curcumin to counteract the oxidative damage to sperm induced by cryopreservation; our results showed that the only concentration tested that was sufficient to produce a positive effect on human sperm cells after thawing was $20 \mu \mathrm{M}$. In fact, supplementation of $20 \mu \mathrm{M}$ curcumin to sperm freezing medium could improve sperm parameters and decrease oxidative damage, preserving sperm DNA fragmentation by suppressing ROS production and GPX4 gene overexpression. Further studies should clarify the pathways influenced by curcumin supplementation during sperm cryopreservation through the modulation of the expression of other genes involved in oxidative stress, such as SOD and CAT, and by evaluating the expression of apoptotic markers such as Fas and $\mathrm{p} 53$. Although other groups have demonstrated the harmful effect of curcumin at higher concentrations $(1 \mathrm{mM})$ [41], future prospects will be aimed at evaluating the effects of curcumin concentrations between $20 \mu \mathrm{M}$ and $1 \mathrm{mM}$ in sperm freezing medium.

Preserving sperm DNA integrity in the presence of the oxidative stress produced by cryopreservation procedures is important for fertilization outcomes, such as normal development of the embryo, foetus and infant [102-104].

Our findings are of great importance for improving the efficiency of sperm cryopreservation to help infertile/ subfertile men and suggest that antioxidants, in particular curcumin, acting at different levels can restore reproductive capacities in individuals with from oxidative stress-associated dysfunction.

Author Contribution All authors contributed to the study conception and design. Material preparation, data collection and analysis were performed by Filomena Mottola, Concetta Iovine and Nicola Colacurci. The first draft of the manuscript was written by Marianna Santonastaso, and all authors commented on previous versions of the manuscript. Lucia Rocco coordinated the study and helped to draft and revise the manuscript. All authors read and approved the final manuscript.

Funding Open access funding provided by Università degli Studi della Campania Luigi Vanvitelli within the CRUI-CARE Agreement. This research was supported by DiSTABiF research funding.

Data Availability Not applicable.

Code Availability Not applicable.

\section{Declarations}

Ethical Approval The study was granted exemption from ethics approval because the study involved no therapeutic interventions nor any change to our routine sperm analysis.

Consent to Participate All participants provided written informed consent.

Consent for Publication The participants consented to the submission of the study to the journal.

Conflict of Interest The authors declare no competing interests.

Open Access This article is licensed under a Creative Commons Attribution 4.0 International License, which permits use, sharing, adaptation, distribution and reproduction in any medium or format, as long as you give appropriate credit to the original author(s) and the source, provide a link to the Creative Commons licence, and indicate if changes were 
made. The images or other third party material in this article are included in the article's Creative Commons licence, unless indicated otherwise in a credit line to the material. If material is not included in the article's Creative Commons licence and your intended use is not permitted by statutory regulation or exceeds the permitted use, you will need to obtain permission directly from the copyright holder. To view a copy of this licence, visit http://creativecommons.org/licenses/by/4.0/.

\section{References}

1. Di Santo M, Tarozzi N, Nadalini M, Borini A. Human sperm cryopreservation: update on techniques, effect on DNA integrity, and implications for ART. Adv Urol. 2012;2012:12.

2. Mangoli E, Talebi AR, Anvari M, Taheri F, Vatanparast M, Rahiminia $\mathrm{T}$, et al. Vitamin $\mathrm{C}$ attenuates negative effects of vitrification on sperm parameters, chromatin quality, apoptosis and acrosome reaction in neat and prepared normozoospermic samples. Taiwan J Obstet Gynecol. 2018;57(2):200-4.

3. Satorre MM, Breininger E, Beconi MT. Cryopreservation with $\alpha$ tocopherol and Sephadex filtration improved the quality of boar sperm. Theriogenology. 2012;78(7):1548-56.

4. Holt WV. Alternative strategies for the long-term preservation of spermatozoa. Reprod Fertil Dev. 1997;9(3):309-19. https://doi. org/10.1071/r96082.

5. Said TM, Gaglani A, Agarwal A. Implication of apoptosis in sperm cryoinjury. Reprod BioMed Online. 2010;21:456-62.

6. Boitrelle F, Albert M, Theillac C, Ferfouri F, Bergere M, Vialard $\mathrm{F}$, et al. Cryopreservation of human spermatozoa decreases the number of motile normal spermatozoa, induces nuclear vacuolization and chromatin decondensation. J Androl. 2012;33(6):1371-8.

7. Chohan KR, Griffin JT, Carrell DT. Evaluation of chromatin integrity in human sperm using acridine orange staining with different fixatives and after cryopreservation. Andrologia. 2004;36(5): 321-6.

8. Kopeika J, Thornhill A, Khalaf Y. The effect of cryopreservation on the genome of gametes and embryos: principles of cryobiology and critical appraisal of the evidence methods. Hum Reprod Update. 2015;21(2):209-27.

9. Griveau JF, Le Lannou D. Reactive oxygen species and human spermatozoa: Physiology and pathology. Int J Androl. 1997;20: 61-9.

10. Calamera JC, Fernandez PJ, Buffone MG, Acosta AA, Doncel GF. Effects of long-term in vitro incubation of human spermatozoa: functional parameters and catalase effect. Andrologia. 2001;33(2):79-86.

11. Sikka SC. Oxidative stress and role of antioxidants in normal and abnormal sperm function. Front Biosci. 1996;1:e78-86.

12. Pons-Rejraji H, Sion B, Saez F, Brugnon F, Janny L, Grizard G. Role of reactive oxygen species (ROS) on human spermatozoa and male infertility. Gynecol Obstet Fertil. 2009;37(6):529-35.

13. Baker MA, Aitken RJ. Reactive oxygen species in spermatozoa: methods for monitoring and significance for the origins of genetic disease and infertility. Reprod Biol Endocrinol. 2005;3:67. https:// doi.org/10.1186/1477-7827-3-67.

14. He L, He T, Farrar S, Ji L, Liu T, Ma X. Antioxidants maintain cellular redox homeostasis by elimination of reactive oxygen species. Cell Physiol Biochem. 2017;44(2):532-53. https://doi.org/ 10.1159/000485089.

15. Paradiso Galatioto G, Gravina GL, Angelozzi G, Sacchetti A, Innominato PF, Pace $\mathrm{G}$, et al. May antioxidant therapy improve sperm parameters of men with persistent oligospermia after retrograde embolization for varicocele? World J Urol. 2008;26(1):97-102.

16. Sinclair S. Male Infertility: Nutritional and Environmental Considerations. Altern Med Rev. 2000;5(1):28-38.

17. Iovine C, Mottola F, Santonastaso M, Finelli R, Agarwal A, Rocco L. In vitro ameliorative effects of ellagic acid on vitality, motility and DNA quality in human spermatozoa. Mol Reprod Dev. 2021;88(2):167-74. https://doi.org/10.1002/mrd.23455.

18. Kalthur G, Raj S, Thiyagarajan A, Kumar S, Kumar P, Adiga SK. Vitamin E supplementation in semen-freezing medium improves the motility and protects sperm from freeze-thaw-induced DNA damage. Fertil Steril. 2011;95(3):1149-51.

19. Glander HJ, Schaller J. Hidden effects of cryopreservation on quality of human spermatozoa. Cell Tissue Bank. 2000;1(2): 133-42.

20. Branco CS, Garcez ME, Pasqualotto FF, Erdtman B, Salvador M. Resveratrol and ascorbic acid prevent DNA damage induced by cryopreservation in human semen. Cryobiology. 2010;60(2):2357.

21. Bucak MN, Tuncer PB, Sariözkan S, Başpinar N, Taşpinar M, Coyan $\mathrm{K}$, et al. Effects of antioxidants on post-thawed bovine sperm and oxidative stress parameters: antioxidants protect DNA integrity against cryodamage. Cryobiology. 2010;61(3):248-53.

22. Garcez ME, Dos Santos BC, Lara LV, Pasqualotto FF, Salvador M. Effects of resveratrol supplementation on cryopreservation medium of human semen. Fertil Steril. 2010;94(6):2118-21.

23. Meamar M, Zribi N, Cambi M, Tamburrino L, Marchiani S, Filimberti E, et al. Sperm DNA fragmentation induced by cryopreservation: new insights and effect of a natural extract from Opuntia ficus-indica. Fertil Steril. 2012;98(2):326-33.

24. Silva ECB, Cajueiro JFP, Silva SV, Soares PC, Guerra MMP. Effect of antioxidants resveratrol and quercetin on in vitro evaluation of frozen ram sperm. Theriogenology. 2012;77(8):1722-6.

25. Taylor K, Roberts P, Sanders K, Burton P. Effect of antioxidant supplementation of cryopreservation medium on post-thaw integrity of human spermatozoa. Reprod BioMed Online. 2009;18(2): 184-9.

26. Thomson LK, Fleming SD, Aitken RJ, De Iuliis GN, Zieschang JA, Clark AM. Cryopreservation-induced human sperm DNA damage is predominantly mediated by oxidative stress rather than apoptosis. Hum Reprod. 2009;24:2061-70.

27. Thuwanut P, Chatdarong K, Johannisson A, Bergqvist AS, Söderquist L, Axnér E. Cryopreservation of epididymal cat spermatozoa: effects of in vitro antioxidative enzymes supplementation and lipid peroxidation induction. Theriogenology. 2010;73(8):1076-87.

28. Andrew R, Izzo AA. Principles of pharmacological research of nutraceuticals. Br J Pharmacol. John Wiley and Sons Inc. 2017;174:1177-94.

29. Dai Q, Zhou D, Xu L, Song X. Curcumin alleviates rheumatoid arthritis-induced inflammation and synovial hyperplasia by targeting mTOR pathway in rats. Drug Des Devel Ther. 2018;12:4095-105.

30. Sahin K, Orhan C, Tuzcu Z, Tuzcu M, Sahin N. Curcumin ameliorates heat stress via inhibition of oxidative stress and modulation of Nrf2/HO-1 pathway in quail. Food Chem Toxicol. 2012;50(11):4035-41.

31. Chainani-Wu N. Safety and anti-inflammatory activity of curcumin: a component of tumeric (Curcuma longa). J Altern Complement Med. 2003;9(1):161-8.

32. Ak T, Gülçin İ. Antioxidant and radical scavenging properties of curcumin. Chem Biol Interact. 2008;174:27-3.

33. Wright JS. Predicting the antioxidant activity of curcumin and curcuminoids. J Mol Struct THEOCHEM. 2002;591:207-17.

34. Barclay LRC, Vinqvist MR, Mukai K, Goto H, Hashimoto Y, Tokunaga A, et al. On the antioxidant mechanism of curcumin: 
classical methods are needed to determine antioxidant mechanism and activity. Org Lett. 2000;2:2841-3.

35. Zheng B, McClements DJ. Formulation of more efficacious curcumin delivery systems using colloid science: enhanced solubility, stability, and bioavailability. Molecules. 2020;25(12):2791. https://doi.org/10.3390/molecules25122791.

36. Balogun E, Hoque M, Gong P, Killeen E, Green CJ, Foresti R, et al. Curcumin activates the haem oxygenase-1 gene via regulation of Nrf2 and the antioxidant-responsive element. Biochem J. 2003;371(Pt 3):887-95. https://doi.org/10.1042/BJ20021619.

37. Farzaei MH, Zobeiri M, Parvizi F, El-Senduny FF, Marmouzi I, Coy-Barrera E, et al. Curcumin in liver diseases: a systematic review of the cellular mechanisms of oxidative stress and clinical perspective. Nutrients. 2018;10(7):855. https://doi.org/10.3390/ nu10070855).

38. Alizadeh F, Javadi M, Karami AA, Gholaminejad F, Kavianpour M, Haghighian HK. Curcumin nanomicelle improves semen parameters, oxidative stress, inflammatory biomarkers, and reproductive hormones in infertile men: A randomized clinical trial. Phytother Res. 2018;32(3):514-21.

39. Fakhrildin MBM. Role of alcoholic turmeric (Curcuma longa) extract in outcome of in vitro sperm activation for infertile patients. Iraqi J Med Sci. 2011;9(4):301-7.

40. Soni PK, Luhadia G, Sharma DK, Mali PC. Antifertility activates of traditional medicinal plants in male with emphasis on their mode action: A review. J Glob Biosci. 2015;4(1):1165-79.

41. Zhou Q, Wu X, Liu Y, Wang X, Ling X, Ge H, et al. Curcumin improves asthenozoospermia by inhibiting reactive oxygen species reproduction through nuclear factor erythroid 2-related factor 2 activation. Andrologia. 2020;52(2):e13491. https://doi.org/10. 1111/and.13491.

42. Karimi S, Khorsandi L, Nejaddehbashi F. Protective effects of curcumin on testicular toxicity induced by titanium dioxide nanoparticles in mice. J Bras Reprod Assist. 2019;23(4):344-51.

43. Giannessi F, Giambelluca MA, Grasso L, Scavuzzo MCRR. Curcumin protects Leydig cells of mice from damage induced by chronic alcohol administration - PubMed. Med Sci Monit. 2008;14:BR237-4.

44. Ozlem Ilbey Y, Ozbek E, Cekmen M, Simsek A, Otunctemur A, Somay A. Protective effect of curcumin in cisplatin-induced oxidative injury in rat testis: mitogen-activated protein kinase and nuclear factor-kappa B signaling pathways. Hum Reprod. 2004;24(7):1717-25.

45. Verma RJ, Mathuria N. Curcumin ameliorates aflatoxin-induced lipid-peroxidation in liver and kidney of mice. Acta Pol Pharm. 2008;65(2):195-202.

46. Noorafshan A, Karbalay-Doust S, Valizadeh A, Aliabadi E, Mirkhani H. Ameliorative effects of curcumin on the seminiferous epithelium in metronidazole-treated mice: a stereological study. Toxicol Pathol. 2010;38(3):366-71.

47. Wei SM, Yan ZZ, Zhou J. Curcumin attenuates ischemiareperfusion injury in rat testis. Fertil Steril. 2009;91(1):271-7.

48. Salama FAE-BS. Effect of curcumin on cadmium-induced oxidative testicular damage in rats. J Med Res Inst. 2007;28:167-73.

49. Lotempio MM, Veena MS, Steele HL, Ramamurthy B, Ramalingam TS, Cohen AN, et al. Curcumin suppresses growth of head and neck squamous cell carcinoma. Clin Cancer Res. 2005;11(19 I):6994-7002.

50. Bucak MN, Bașpınar N, Tuncer PB, Çoyan K, Sarı̈zkan S, Akalın PP, et al. Effects of curcumin and dithioerythritol on frozen-thawed bovine semen. Andrologia. 2012;44(SUPPL.1): $102-9$.

51. Soleimanzadeh A, Saberivand A. Effect of curcumin on rat sperm morphology after the freeze-thawing process. Vet Res Forum. 2013;4(3):185-9.
52. Shah SAH, Andrabi SMH, Ahmed H, Qureshi IZ. Cryoprotection synergism between glycerol and dimethyl sulfoxide improves the mitochondrial transmembrane potential, plasmalemma, acrosomal and DNA integrities, and in vivo fertility of water buffalo (Bubalus bubalis) spermatozoa. Cytotechnology. 2016;68(6): 2335-44.

53. Chanapiwat $\mathrm{P}, \mathrm{Kaeoket} \mathrm{K}$. The effect of Curcuma longa extracted (curcumin) on the quality of cryopreserved boar semen. Anim Sci J. 2015;86(9):863-8.

54. Sahoo DK, Roy A, Chainy GBN. Protective effects of vitamin E and curcumin on 1-thyroxine-induced rat testicular oxidative stress. Chem Biol Interact. 2008;176(2-3):121-8.

55. Tvrdá E, Tušimová E, Kováčik A, Paál D, Greifová H, Abdramanov A, et al. Curcumin has protective and antioxidant properties on bull spermatozoa subjected to induced oxidative stress. Anim Reprod Sci. 2016;172:10-20.

56. Omur AD, Coyan K. Protective effects of the antioxidants curcumin, ellagic acid and methionine on motility, mitochondrial transmembrane potential, plasma membrane and acrosome integrity in freeze-thawed Merino ram sperm. Vet Med (Praha). 2016;61(1):10-6.

57. Ingold I, Aichler M, Yefremova E, Roveri A, Buday K, Doll S, et al. Expression of a catalytically inactive mutant form of glutathione peroxidase $4(\mathrm{Gpx} 4)$ confers a dominant-negative effect in male fertility. J Biol Chem. 2015;290(23):14668-78.

58. Imai H, Hakkaku N, Iwamoto R, Suzuki J, Suzuki T, Tajima Y, et al. Depletion of selenoprotein GPx4 in spermatocytes causes male infertility in mice. J Biol Chem. 2009;284(47):32522-32.

59. WHO. WHO laboratory manual for the Examination and processing of human semen. World Heal Organ. 2010; $5^{\mathrm{a}}$ edition.

60. Santonastaso M, Mottola F, Iovine C, Cesaroni F, Colacurci N, Rocco L. In vitro effects of titanium dioxide nanoparticles $\left(\mathrm{TiO}_{2} \mathrm{NPs}\right)$ on cadmium chloride $\left(\mathrm{CdCl}_{2}\right)$ genotoxicity in human sperm cells. Nanomaterials. 2020;10(6):1118.

61. Santonastaso M, Mottola F, Colacurci N, Iovine C, Pacifico S, Cammarota $\mathrm{M}$, et al. In vitro genotoxic effects of titanium dioxide nanoparticles $\left(\mathrm{n}-\mathrm{TiO}_{2}\right)$ in human sperm cells. Mol Reprod Dev. 2019;86(10):1369-77.

62. Meseguer M, Garrido N, Simón C, Pellicer A, Remohí J. Concentration of glutathione and expression of glutathione peroxidases 1 and 4 in fresh sperm provide a forecast of the outcome of cryopreservation of human spermatozoa. J Androl. 2004;25(5): 773-80. https://doi.org/10.1002/j.1939-4640.2004.tb02855.x.

63. Garrido N, Meseguer M, Alvarez J, Simón C, Pellicer A, Remohí J. Relationship among standard semen parameters, glutathione peroxidase/glutathione reductase activity, and mRNA expression and reduced glutathione content in ejaculated spermatozoa from fertile and infertile men. Fertil Steril. 2004;82(Suppl 3):1059-66. https://doi.org/10.1016/j.fertnstert.2004.04.033.

64. Marianna S, Alessia P, Susan C, Francesca C, Angela S, Francesca $\mathrm{C}$, et al. Metabolomic profiling and biochemical evaluation of the follicular fluid of endometriosis patients. Mol BioSyst. 2017;13(6):1213-22 [published correction appears in Mol Biosyst. 2017 May 30;13(6):1246].

65. Mottola F, Iovine C, Santonastaso M, Romeo ML, Pacifico S, Cobellis L, et al. NPs-TiO2 and lincomycin coexposure induces DNA damage in cultured human amniotic cells. Nanomaterials. 2019;9(11):1511. https://doi.org/10.3390/nano9111511.

66. Talaei T, Esmaeelpour T, Aekiyash F, et al. Effects of cryopreservation on plasma membrane glycoconjugates of human spermatozoa. J Reprod Med. 2010;8:119-24.

67. Nazm Bojnordi M, Movahedin M, Amanpour S, et al. Effect of antioxidants supplementation on human sperm parameters after freezing. MazUMS. 2008;18:20-7.

68. Karimfar MH, Niazvand F, Haghani K, Ghafourian S, Shirazi R, Bakhtiyari S. The protective effects of melatonin against 
cryopreservation-induced oxidative stress in human sperm. Int $\mathrm{J}$ Immunopathol Pharmacol. 2015;28(1):69-76.

69. Johnson LA, Weitze KF, Fiser P, Maxwell WMC. Storage of boar semen. Anim Reprod Sci. 2000;62(1-3):143-72.

70. Hezavehei M, Sharafi M, Kouchesfahani HM, Henkel R, Agarwal A, Esmaeili V, et al. Sperm cryopreservation: A review on current molecular cryobiology and advanced approaches. Reprod BioMed Online. 2018;37:327-39.

71. Johnston SD, Satake N, Zee Y, López-Fernández C, Holt WV, Gosálvez J. Osmotic stress and cryoinjury of koala sperm: an integrative study of the plasma membrane, chromatin stability and mitochondrial function. Reproduction. 2012;143(6):787-97.

72. Agarwal A, Prabakaran SA, Said TM. Prevention of oxidative stress injury to sperm. J Androl. 2005;26:654-60.

73. Leisegang K, Henkel R, Agarwal A. Redox regulation of fertility in aging male and the role of antioxidants: a savior or stressor. Curr Pharm Des. 2017;23(30):4438-50. https://doi.org/10.2174/ 1381612822666161019150241.

74. Wang S, Wang W, Xu Y, Tang M, Fang J, Sun H, et al. Proteomic characteristics of human sperm cryopreservation. Proteomics. 2014;14(2-3):298-310.

75. Fingerova H, Novotny J, Barborik J, Brezinova J, Svobodova M, Krskova M, et al. Antioxidant capacity of seminal plasma measured by TAS Randox. Biomed Pap Med Fac Univ Palacky Olomouc Czech Repub. 2007;151(1):37-40.

76. Deng S, Yu K, Jiang W, Li Y, Wang S, Deng Z, et al. Overexpression of Toll-like receptor 2 up-regulates heme oxygenase1 expression and decreases oxidative injury in dairy goats. J Anim Sci Biotechnol. 2017;8(3). https://doi.org/10.1186/s40104-0160136-2.

77. Rocco L, Mottola F, Santonastaso M, Saputo V, Cusano E, Costagliola D, et al. Anti-genotoxic ability of $\alpha$-tocopherol and Anthocyanin to counteract fish DNA damage induced by musk xylene. Ecotoxicology. 2015;24(9):2026-35.

78. Mottola F, Scudiero N, Iovine C, Santonastaso M, Rocco L. Protective activity of ellagic acid in counteract oxidative stress damage in zebrafish embryonic development. Ecotoxicol Environ Saf. 2020;197:110642.

79. Aghaz F, Khazaei M, Vaisi-Raygani A, Bakhtiyari M. Cryoprotective effect of sericin supplementation in freezing and thawing media on the outcome of cryopreservation in human sperm. Aging Male. 2018:1-8. https://doi.org/10.1080/ 13685538.2018.1529156.

80. Deng SL, Sun TC, Yu K, Wang ZP, Zhang BL, Zhang Y, et al. Melatonin reduces oxidative damage and upregulates heat shock protein 90 expression in cryopreserved human semen. Free Radic Biol Med. 2017;113:347-54.

81. Zribi N, Chakroun NF, Ben Abdallah F, Elleuch H, Sellami A, Gargouri J, et al. Effect of freezing-thawing process and quercetin on human sperm survival and DNA integrity. Cryobiology. 2012;65(3):326-31.

82. Iqbal M, Sharma SD, Okazaki Y, Fujisawa M, Okada S. Dietary supplementation of curcumin enhances antioxidant and phase II metabolizing enzymes in ddY male mice: possible role in protection against chemical carcinogenesis and toxicity. Pharmacol Toxicol. 2003;92(1):33-8.

83. Chen AL, Hsu CH, Lin JK, Hsu MM, Ho YF, She TS, et al. Phase I clinical trial of curcumin, a chemopreventive agent, in patients with high-risk or pre-malignant lesions. Anticancer Res. 2001;21(4 B):2895-900.

84. Chenlo PH, Curi SM, Pugliese MN, Ariagno JI, Sardi-Segovia M, Furlan MJ, et al. Fragmentation of sperm DNA using the TUNEL method. Actas Urol Esp. 2014;38(9):608-12.

85. Foresta C, Flohe L, Garolla A, Roveri A, Ursini F, Maiorino M. Male fertility is linked to the selenoprotein phospholipid hydroperoxide glutathione peroxidase. Biol Reprod. 2002;67:967-71.
86. Maiorino M, Bosello V, Ursini F, Foresta C, Garolla A, Scapin M, et al. Genetic variations of gpx-4 and male infertility in humans. Biol Reprod. 2003;68:1134-41.

87. Imai H, Nakagawa Y. Biological significance of phospholipid hydroperoxide glutathione peroxidase (PHGPx, GPx4) in mammalian cells. Free Radic Biol Med. 2003;34(2):145-69.

88. Imai H, Suzuki K, Ishizaka K, Ichinose S, Oshima H, Okayasu I, et al. Failure of the expression of phospholipid hydroperoxide glutathione peroxidase in the spermatozoa of human infertile males. In: Biol Reprod. Society for the Study of Reproduction 2001;64(2):674-83.

89. Conrad M, Schneider M, Seiler A, Bornkamm GW. Physiological role of phospholipid hydroperoxide glutathione peroxidase in mammals. Biol Chem. 2007;388(10):1019-25.

90. Garolla A, Maiorino M, Roverato A, Roveri A, Ursini F, Foresta C. Oral carnitine supplementation increases sperm motility in asthenozoospermic men with normal sperm phospholipid hydroperoxide glutathione peroxidase levels. Fertil Steril. 2005;83(2): 355-61.

91. Pfeifer H, Conrad M, Roethlein D, Kyriakopoulos A, Brielmeier $\mathrm{M}$, Bornkamm GW, et al. Identification of a specific sperm nuclei selenoenzyme necessary for protamine thiol cross-linking during sperm maturation. FASEB J. 2001;15:1236-8.

92. Tramer F, Vetere A, Martinelli M, Paroni F, Marsich E, Boitani C, et al. cAMP-response element modulator- $\tau$ activates a distinct promoter element for the expression of the phospholipid hydroperoxide/sperm nucleus glutathione peroxidase gene. Biochem J. 2004;383(1):179-85.

93. Conrad M, Moreno SG, Sinowatz F, Ursini F, Kölle S, Roveri A, et al. The nuclear form of phospholipid hydroperoxide glutathione peroxidase is a protein thiol peroxidase contributing to sperm chromatin stability. Mol Cell Biol. 2005;25(17):7637-44.

94. Quan C, Shi Y, Wang C, Wang C, Yang K. p,p'-DDE damages spermatogenesis via phospholipid hydroperoxide glutathione peroxidase depletion and mitochondria apoptosis pathway. Environ Toxicol. 2016;31(5):593-600.

95. Aparnak P, Saberivand A. Effects of curcumin on canine semen parameters and expression of nox 5 gene in cryopreserved spermatozoa. Vet Res Forum. 2019;10(3):221-6.

96. Tvrdá E, Lukáč N, Jambor T, Lukáčová J, Massányi P. Curcumin in male fertility: effects on spermatozoa vitality and oxidative balance. J Microbiol Biotechnol Food Sci. 2015;04(Special issue 2):120-4.

97. Cohly HHP, Taylor A, Angel MF, Salahudeen AK. Effect of turmeric, turmerin and curcumin on $\mathrm{H} 2 \mathrm{O} 2$-induced renal epithelial (LLC-PK1) cell injury. Free Radic Biol Med. 1998;24(1):4954.

98. Sreejayan, Rao MN. Curcuminoids as potent inhibitors of lipid peroxidation. J Pharm Pharmacol. 1994;46(12):1013-6.

99. Xie Z, Wu B, Shen G, Li X, Wu Q. Curcumin alleviates liver oxidative stress in type 1 diabetic rats. Mol Med Rep. 2018;17(1):103-8.

100. Singh S, Aggarwal BB. Activation of transcription factor NF-kB is suppressed by curcumin (diferulolylmethane). $\mathrm{J}$ Biol Chem. 1995;270(42):24995-5000.

101. Naz RK. The effect of curcumin on intracellular $\mathrm{pH}$ (pHi), membrane hyperpolarization and sperm motility. J Reprod Infertil. 2014;15(2):62-70.

102. Waterhouse KE, Gjeldnes A, Tverdal A, De Angelis PM, Farstad $\mathrm{W}$, Håård $\mathrm{M}$, et al. Alterations of sperm DNA integrity during cryopreservation procedure and in vitro incubation of bull semen. Anim Reprod Sci. 2010;117(1-2):34-42.

103. Gandini L, Lombardo F, Lenzi A, Spanò M, Dondero F. Cryopreservation and sperm DNA integrity. Cell Tissue Bank. 2006;7(2):91-8. 